\title{
Effects of Taurine Supplementation on the Growth Performance of Juvenile Rock Bream Oplegnathus fasciatus
}

\author{
Fernando Magalhaes Ferreira, Hyeonho Yun, Youngjin Park, Gunhyun Park, Sera Choi and Sungchul C Bai* \\ Department of Marine Bio-Materials \& Aquaculture/ Feeds and Foods Nutrition Research Center, Pukyong National University, \\ Busan 608-737, Korea
}

\begin{abstract}
An 8-week feeding trial was conducted to investigate the effects of dietary taurine supplementation on the growth performance of juvenile rock bream, Oplegnathus fasciatus. Triplicate groups of 25 fish averaging $2.72 \pm 0.04 \mathrm{~g}$ (mean $\pm \mathrm{SD}$ ) were fed one of six experimental diets prepared by adding taurine at $0 \%, 0.25 \%, 0.5 \%, 1.0 \%, 1.5 \%$ and $3.0 \%\left(\right.$ Control, $\mathrm{Tau}_{0.25}, \mathrm{Tau}_{0.5}, \mathrm{Tau}_{1.0}$, $\mathrm{Tau}_{1.5}$ and $\mathrm{Tau}_{3.0}$, respectively). At the end of the feeding trial, the weight gain, specific growth rate and protein efficiency ratio of fish fed the $\mathrm{Tau}_{0.5}, \mathrm{Tau}_{1.0}$ and $\mathrm{Tau}_{1.5}$ diets were significantly higher $(P<0.05)$ than those of fish fed the Control and $\mathrm{Tau}_{0.25}$ diets. The feed efficiency of fish fed the $\mathrm{Tau}_{0.5}$ diet was significantly higher than that of fish fed the Control, $\mathrm{Tau}_{0.25} \mathrm{and} \mathrm{Tau}_{3.0}$ diets. Fish fed the $\mathrm{Tau}_{1.0}$ diet had higher whole-body crude protein content than fish fed the Control diet, while the crude lipid content of fish fed the $\mathrm{Tau}_{1.5}$ and $\mathrm{Tau}_{3.0}$ diets was significantly lower than that of fish fed the Control and $\mathrm{Tau}_{0.25}$ diets. An ANOVA suggested that the optimum level of dietary taurine supplementation to improve growth and reduce the body lipid contents of juvenile rock bream, $O$. fasciatus, was $0.5 \%$, while a broken line analysis of weight gain indicated a level of $0.62 \%$.
\end{abstract}

Key words: Taurine, Feed additive, Growth performance, Rock bream, Oplegnathus fasciatus

\section{Introduction}

Rock bream, Oplegnathus fasciatus, is an economically important marine fish in East Asia. In 2012, its aquaculture production in Korea was approximately 650 metric tonnes (MOMAF, 2014). In recent years, accompanying the growing interest in culturing this species, there has been an increase in the number of published studies on the nutrition of $O$. fasciatus (Kang et al., 1998; Wang et al., 2003; Kim et al., 2008a; Lim and Lee, 2009; Hwang et al., 2013; Kim et al., 2013a, 2013b). However, to date, limited information is available on dietary additives that promote the growth of this species (Ko et al., 2008; Lim et al., 2013).

Taurine (2-aminoethanesulfonic acid) is a dietary supplement used to promote growth in aquaculture. It is the most abundant free amino acid in living organisms, and is involved in numerous important biological functions, including membrane stabilization, detoxification, anti-oxidation, modulation of the immune response, calcium transport, retina development, bile acid metabolism, osmotic regulation, and endocrine functions (Kuzmina et al., 2010; El-Sayed, 2013). Historically, taurine has not been considered an essential nutrient for fish; however, the taurine requirement in marine finfish was recently reported to be $2.6-72.0 \mathrm{mg}$ taurine/g diet (Rhodes and Davis, 2011).

Dietary taurine supplementation to farmed finfish has been shown to reduce nutritional diseases, such as green liver, regulate hematocrit levels (Rhodes and Davis, 2011), and reduce body lipid content (Kim et al., 2008b; Espe et al., 2012), and is considered an essential nutrient for promotion of growth
(C) 2014 The Korean Society of Fisheries and Aquatic Science This is an Open Access article distributed under the terms of the Creative Commons Attribution Non-Commercial Licens (http://creativecommons. org/licenses/by-nc/3.0/) which permits unrestricted non-commercial use distribution, and reproduction in any medium, provided the original work is properly cited.
Received 27 March 2014; Revised 09 May 2014

Accepted 10 May 2014

*Corresponding Author

E-mail: scbai@pknu.ac.kr 
performance in several species (Park et al., 2002; Kim et al., 2003, 2005a, 2005b; Takagi et al., 2006, 2011; Gaylord et al., 2007; Lunger et al., 2007; Kim et al., 2008b; Qi et al., 2012), including rock bream (Lim et al., 2013).

The objective of this study was to investigate the effects of dietary taurine supplementation on the growth performance of juvenile rock bream, $O$. fasciatus.

\section{Materials and Methods}

\section{Experimental diets}

Six experimental diets using fish meal as the main protein source were prepared by adding taurine at $0 \%, 0.25 \%, 0.5 \%$, $1.0 \%, 1.5 \%$ and $3.0 \%$ (designated as Control, $\mathrm{Tau}_{0.25}, \mathrm{Tau}_{0.5}$, $\mathrm{Tau}_{1.0}, \mathrm{Tau}_{1.5}$ and $\mathrm{Tau}_{3.0}$, respectively), as shown in Table 1. The experimental diets were formulated to be isonitrogenous (49\% crude protein) and isocaloric $(17 \mathrm{~kJ} / \mathrm{g})$. The energy levels of the diets were calculated based on 23.6, 17.2 and 39.5 $\mathrm{kJ} / \mathrm{g}$ for protein, carbohydrate and lipids, respectively (NRC, 2011). The dietary cysteine and methionine concentrations were similar among the experimental diets. Dietary taurine (Korea Bio-gen, Cheonan, Korea) concentration (mg/g diet) increased proportionally with taurine supplementation level, and was 0.8 in Control, 3.2 in $\mathrm{Tau}_{0.25}, 5.7$ in $\operatorname{Tau}_{0.5}, 10.7$ in
$\mathrm{Tau}_{1.0}, 15.6$ in $\mathrm{Tau}_{1.5}$ and 30.5 in $\mathrm{Tau}_{3.0}$. The experimental diets were prepared by thoroughly mixing the dry ingredients in an electric mixer, followed by addition of oil and distilled water. This mixture was formed into dough, and pellets were produced by passing the dough through a screw-type pelleting machine and air drying the formed pellets for $48 \mathrm{~h}$. After drying, the pellets were ground, sieved into the required pellet size, packed and stored at $-20^{\circ} \mathrm{C}$ until use.

\section{Experimental fish and feeding trial}

Juvenile rock bream, O. fasciatus, were obtained from a commercial hatchery (Hungmin, Tongyoung, Korea) and transported to the Feeds and Foods Nutrition Research Center, Pukyong National University, Busan, South Korea. Prior to initiation of the feeding trial, all fish were acclimated to the experimental conditions and fed the Control diet for 10 days. Groups of 25 randomly chosen fish with an initial body weight of $2.72 \pm 0.04 \mathrm{~g}$ (mean $\pm \mathrm{SD}$ ) were randomly stocked into each of 18 aquariums $(40 \mathrm{~L})$. The six experimental diets were fed to triplicate groups of fish twice a day for 8 weeks. The feeding rate was adjusted from 4\% BW (body weight)/day to $3 \%$ $\mathrm{BW} /$ day at week 4 . The total fish weight in each aquarium was determined biweekly and the amount of diet fed to the fish was adjusted accordingly. Feeding was stopped $24 \mathrm{~h}$ prior to weighing to minimize the stress of the fish. The feeding trial

Table 1. Formulation and proximate composition of experimental diets (\% dry matter)

\begin{tabular}{|c|c|c|c|c|c|c|}
\hline \multirow{2}{*}{ Ingredients (\%) } & \multicolumn{6}{|c|}{ Diets $^{1}$} \\
\hline & Control & $\operatorname{Tau}_{0.25}$ & $\operatorname{Tau}_{0.5}$ & $\mathbf{T a u}_{1.0}$ & $\mathrm{Tau}_{1.5}$ & $\mathrm{Tau}_{3.0}$ \\
\hline Fish meal $^{2}$ & 50.0 & 50.0 & 50.0 & 50.0 & 50.0 & 50.0 \\
\hline Wheat gluten meal ${ }^{2}$ & 13.0 & 12.6 & 12.3 & 11.7 & 11.1 & 9.3 \\
\hline Wheat flour ${ }^{2}$ & 19.0 & 19.0 & 19.0 & 19.0 & 19.0 & 19.0 \\
\hline Corn starch ${ }^{2}$ & 4.0 & 4.0 & 4.0 & 4.0 & 4.0 & 4.0 \\
\hline Cellulose $^{2}$ & 0.0 & 0.1 & 0.2 & 0.3 & 0.4 & 0.7 \\
\hline Fish oil $^{2}$ & 10.0 & 10.0 & 10.0 & 10.0 & 10.0 & 10.0 \\
\hline Vitamin premix $^{3}$ & 2.0 & 2.0 & 2.0 & 2.0 & 2.0 & 2.0 \\
\hline Mineral premix ${ }^{4}$ & 2.0 & 2.0 & 2.0 & 2.0 & 2.0 & 2.0 \\
\hline Taurine ${ }^{5}$ & 0.0 & 0.25 & 0.5 & 1.0 & 1.5 & 3.0 \\
\hline \multicolumn{7}{|c|}{ Proximate composition (\% - dry matter basis) } \\
\hline Crude Protein & 49.7 & 49.2 & 50.2 & 49.0 & 48.5 & 48.9 \\
\hline Crude Lipid & 14.5 & 15.4 & 14.4 & 14.6 & 12.7 & 12.2 \\
\hline Ash & 12.4 & 11.4 & 11.7 & 11.8 & 12.1 & 11.6 \\
\hline Moisture & 11.5 & 11.5 & 11.8 & 11.6 & 11.6 & 12.0 \\
\hline Energy $(\mathrm{kJ} / \mathrm{g})$ & 17.8 & 17.8 & 17.8 & 17.8 & 17.8 & 17.8 \\
\hline Taurine (mg/g) & 0.8 & 3.2 & 5.7 & 10.7 & 15.6 & 30.5 \\
\hline Methionine + Cysteine $(\mathrm{mg} / \mathrm{g})$ & 2.0 & 2.0 & 2.0 & 2.1 & 2.1 & 2.0 \\
\hline
\end{tabular}

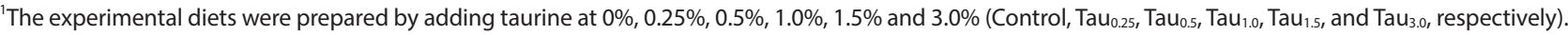
${ }^{2}$ Supplied by Suhyup Feed Company, Busan, Korea.

${ }^{3}$ Contains (as mg/kg diet): Ascorbic acid, 300; dl-Calcium pantothenate, 150; Choline bitatrate, 3000; Inositol, 150; Menadione, 6; Niacin, 150; Pyridoxine. HCl, 15; Riboflavin, 30; Thiamine mononitrate, 15; dl-a-Tocopherol acetate, 201; Retinyl acetate, 6; Biotin, 1.5; Folic acid, 5.4; B12, 0.06.

${ }^{4}$ Contains (as mg/kg diet): $\mathrm{NaCl}, 437.4 ; \mathrm{MgSO}_{4} 7 \mathrm{H}_{2} \mathrm{O}, 1379.8 ; \mathrm{NaH}_{2} \mathrm{P}_{4} 2 \mathrm{H}_{2} \mathrm{O}, 877.8 ; \mathrm{Ca}(\mathrm{H} 2 \mathrm{PO} 4)_{2} 2 \mathrm{H}_{2} \mathrm{O}, 1366.7 ; \mathrm{K}_{2} \mathrm{HPO}_{4}, 2414 ; \mathrm{ZnSO}_{4}$ 7 $\mathrm{H}_{2} \mathrm{O}, 226.4 ; \mathrm{Fe}-\mathrm{Citrate}, 299$; Ca-lactate, 3004; $\mathrm{MnSO}_{4}, 0.016 ; \mathrm{FeSO}_{4}, 0.0378 ; \mathrm{CuSO}_{4}, 0.00033 ;$ Calcium iodate, $0.0006 ; \mathrm{MgO}, 0.00135 ; \mathrm{NaSeO}, 0.00025$.

${ }^{5}$ Supplied by Korea Bio-gen, Cheonan, Korea. 
was conducted in an indoor semi-recirculation sea water system. Throughout the experiment, the water temperature was maintained at $20 \pm 1{ }^{\circ} \mathrm{C}$ by a cooler at the water supply tank, water flow was $2.6 \mathrm{~L} / \mathrm{min}$, dissolved oxygen was maintained above $7.5 \mathrm{mg} / \mathrm{L}$, salinity was $31 \pm 1 \mathrm{ppm}$ and $\mathrm{pH}$ was $7.7 \pm$ 0.1 .

\section{Sample collection and analysis}

At the end of the feeding trial, the fish were starved for $24 \mathrm{~h}$, then counted and weighed to calculate weight gain (WG), feed efficiency (FE), specific growth rate (SGR), protein efficiency ratio (PER) and survival. After the final weighing, three fish per tank were selected randomly and used for determination of the hepatosomatic index (HSI) and condition factor (CF). Random samples of 10 fish per tank at the beginning of the feeding trial and 10 fish per tank at the end of the trial were selected, minced and stored at $-20^{\circ} \mathrm{C}$ until whole-body proximate composition and free amino acid (taurine, methionine and cysteine) analysis. The proximate compositions of the experimental diets and whole bodies of fish were analyzed according to standard methods (AOAC, 2006). Samples of the diets and fish were dried at $110^{\circ} \mathrm{C}$ for $24 \mathrm{~h}$ in a drying oven to determine their moisture content. Ash content was determined by incineration at $600^{\circ} \mathrm{C}$ in a muffle furnace. Crude protein content was determined using the Kjeldahl method $(N \times 6.25)$ after acid digestion, and crude lipid contents were determined by the soxhlet extraction using the Soxtec system 1046 (Foss, Hoganas, Sweden) after freeze-drying for $12 \mathrm{~h}$. Samples were prepared for free amino acid analysis by homogenizing the whole bodies of fish in $1 \%$ sulphosalicylic acid, followed by centrifugation at $3000 \mathrm{~g}$ for $20 \mathrm{~min}$ at $4^{\circ} \mathrm{C}$. Free amino acid concentrations were determined individually using a Skyam S-433 automatic amino acid analyzer (Sykam, Eresing, Germany).

\section{Statistical analyses}

All data were analyzed by one-way ANOVA. When a significant effect of the treatments was identified, a least significant difference (LSD) test was used to compare means. Treatment effects were considered significant at $P<0.05$. Broken line regression analysis (Robbins et al., 1979) was applied to determine the optimum inclusion level of taurine in the diet of juvenile rock bream. Also, the maximum dietary taurine supplementation level was determined by subjecting the response variables to second-degree polynomial regression analysis $(\mathrm{Y}$ $=\mathrm{aX}+\mathrm{bX}+\mathrm{C})$; the maximum supplementation was determined as the point at which the maximum slope of the curve was reduced by $95 \%$ (Baker, 1986). All statistical analyses were carried out using the SAS version 9.1 software (SAS Institute, Cary, NC, USA).

\section{Results}

Percent weight gain (WG), feed efficiency (FE), specific growth rate (SGR), protein efficiency ratio (PER), hepatosomatic index (HSI), condition factor (CF) and survival rate data are summarized in Table 2. After the feeding trial, the WG, SGR and PER of fish fed the $\mathrm{Tau}_{0.5}, \mathrm{Tau}_{1.0}$ and $\mathrm{Tau}_{1.5}$ diets were significantly higher than those of fish fed the Control

Table 2. Growth performance of juvenile rock bream fed the experimental diets for 8 weeks ${ }^{1}$

\begin{tabular}{|c|c|c|c|c|c|c|c|}
\hline & \multicolumn{6}{|c|}{ Diets $^{2}$} & \multirow{2}{*}{ Pooled SEM ${ }^{3}$} \\
\hline & Control & $\operatorname{Tau}_{0.25}$ & $\mathbf{T a u}_{0.5}$ & $\operatorname{Tau}_{1.0}$ & $\mathbf{T a u}_{1.5}$ & $\mathbf{T a u}_{3.0}$ & \\
\hline $\operatorname{IBW}(\mathrm{g})^{4}$ & 2.75 & 2.76 & 2.66 & 2.72 & 2.75 & 2.68 & 0.04 \\
\hline $\mathrm{FBW}(\mathrm{g})^{5}$ & $7.38^{\mathrm{b}}$ & $7.48^{\mathrm{b}}$ & $7.69^{\mathrm{ab}}$ & $7.94^{\mathrm{ab}}$ & $8.10^{\mathrm{a}}$ & $7.50^{\mathrm{ab}}$ & 0.02 \\
\hline WG $(\%)^{6}$ & $168.89^{\mathrm{b}}$ & $171.04^{\mathrm{b}}$ & $189.72^{\mathrm{a}}$ & $191.78^{\mathrm{a}}$ & $194.00^{\mathrm{a}}$ & $179.60^{\mathrm{ab}}$ & 0.67 \\
\hline $\mathrm{FE}(\%)^{7}$ & $100.98^{\mathrm{b}}$ & $100.65^{b}$ & $114.88^{\mathrm{a}}$ & $108.77^{\mathrm{ab}}$ & $108.37^{\mathrm{ab}}$ & $104.31^{\mathrm{b}}$ & 0.43 \\
\hline $\operatorname{SGR}(\%)^{8}$ & $2.20^{\mathrm{b}}$ & $2.21^{\mathrm{b}}$ & $2.36^{\mathrm{a}}$ & $2.38^{\mathrm{a}}$ & $2.40^{\mathrm{a}}$ & $2.32^{\mathrm{ab}}$ & 0.01 \\
\hline $\mathrm{PER}^{9}$ & $2.03^{\mathrm{b}}$ & $2.05^{\mathrm{b}}$ & $2.29^{\mathrm{a}}$ & $2.22^{\mathrm{a}}$ & $2.23^{\mathrm{a}}$ & $2.13^{\mathrm{ab}}$ & 0.01 \\
\hline $\mathrm{HSI}^{10}$ & $1.74^{\mathrm{ab}}$ & $1.90^{\mathrm{a}}$ & $1.66^{\mathrm{ab}}$ & $1.82^{\mathrm{a}}$ & $1.67^{\mathrm{ab}}$ & $1.42^{\mathrm{b}}$ & 0.01 \\
\hline $\mathrm{CF}^{11}$ & 1.94 & 1.89 & 1.82 & 1.84 & 1.87 & 1.90 & 0.01 \\
\hline Survival (\%) & 85 & 84 & 81 & 85 & 85 & 87 & 0.01 \\
\hline
\end{tabular}

${ }^{1}$ Values are means from triplicate groups of fish, where the mean in each row with a different letters are significantly different $(P<0.05)$.

${ }^{2}$ Refer to Table 1.

${ }^{3}$ Pooled standard error of mean: SD $/ \sqrt{ } n, n=3$ replicated tanks of fish per diet treatment.

${ }^{4}$ Initial fish wet body weight (g).

${ }^{5}$ Final fish wet body weight $(\mathrm{g})$.

${ }^{6}$ Weight gain (\%), WG $=100 \times$ (final weight - initial weight)/initial weight.

${ }^{7}$ Feed efficiency (\%), FE $=100 \times$ (wet weight gain/dry feed intake).

${ }^{8}$ Specific growth rate (\%), SGR $=100 \times[($ In final weight - In initial weight)/days $]$.

${ }^{9}$ Protein efficiency ratio, PER = wet weight gain/protein intake.

${ }^{10}$ Hepatosomatic index, $\mathrm{HSI}=100 \times$ (liver weight/body weight).

${ }^{11}$ Condition factor, $\mathrm{CF}=100 \times\left[\right.$ fish weight $/$ fish length $\left.\left(\mathrm{cm}^{3}\right)\right]$. 
and $\mathrm{Tau}_{0.25}$ diets $(P<0.05)$; however, there were no significant differences in these variables between fish fed the $\mathrm{Tau}_{0.5}$, $\mathrm{Tau}_{1.0}, \mathrm{Tau}_{1.5}$ and $\mathrm{Tau}_{3.0}$ diets, or between fish fed the Control and $\mathrm{Tau}_{0.25}$ diets. The FE of fish fed the $\mathrm{Tau}_{0.5}$ diet was significantly higher than that of fish fed the Control, $\mathrm{Tau}_{0.25}$ and $\mathrm{Tau}_{3.0}$ diets; however, there were no significant differences in FE between fish fed the $\mathrm{Tau}_{0.5}, \mathrm{Tau}_{1.0}$ and $\mathrm{Tau}_{1.5}$ diets, or between fish fed the Control, $\mathrm{Tau}_{0.25}, \mathrm{Tau}_{1.0}, \mathrm{Tau}_{1.5}$ and $\mathrm{Tau}_{3.0}$ diets. Broken line analysis for WG indicated that the optimum taurine supplementation level was $0.62 \%$ (Fig. 1). Additionally, second-degree polynomial regression analysis of $\mathrm{WG}$ and dietary taurine supplementation levels $\left(\mathrm{Y}_{95 \% \max }=-18.526 \mathrm{x}^{2}\right.$ $\left.+46.329 \mathrm{x}+164.01 ; R^{2}=0.7596\right)$ indicated a maximum taurine supplementation level for juvenile rock bream of $1.25 \%$ (Fig. 2). No clear trend was observed between the increasing level of dietary taurine and changes in HSI of fish fed the experimental diets. There were no significant differences in $\mathrm{CF}$ and survival among fish fed the various experimental diets. An ANOVA suggested that the optimum taurine dietary supplementation level was $0.5 \%$, while broken line analysis of $\mathrm{WG}$ indicated a level of $0.62 \%$ for positive effects on growth and feed utilization in juvenile rock bream.

Data on the proximate composition of juvenile rock bream fed the experimental diets are summarized in Table 3. The whole-body crude lipid content decreased steadily with increasing dietary taurine level. The whole-body lipid contents of fish fed the $\mathrm{Tau}_{1.5}$ and $\mathrm{Tau}_{3.0}$ diets were significantly lower than those of fish fed the Control and $\mathrm{Tau}_{0.25}$ diets; however, there were no significant differences in the whole-body lipid contents among fish fed the $\mathrm{Tau}_{0.5}, \mathrm{Tau}_{1.0}, \mathrm{Tau}_{1.5}$ and $\mathrm{Tau}_{3.0}$ diets, or among fish fed the Control, $\mathrm{Tau}_{0.25}, \mathrm{Tau}_{0.5}$ and $\mathrm{Tau}_{1.0}$ diets. Whole-body protein content trend to increase with the increasing of dietary taurine supplementation up to $1 \%$ and afterwards it was decreased. There were no significant differences in the moisture and ash contents among fish fed the experimental diets.

The taurine and sulfur amino acid (methionine plus cysteine) whole-body concentrations in fish fed the experimental diets are presented in Fig. 3A and 3B, respectively. The whole-body taurine content of fish fed the experimental diets increased with increasing dietary taurine until reaching a pla-

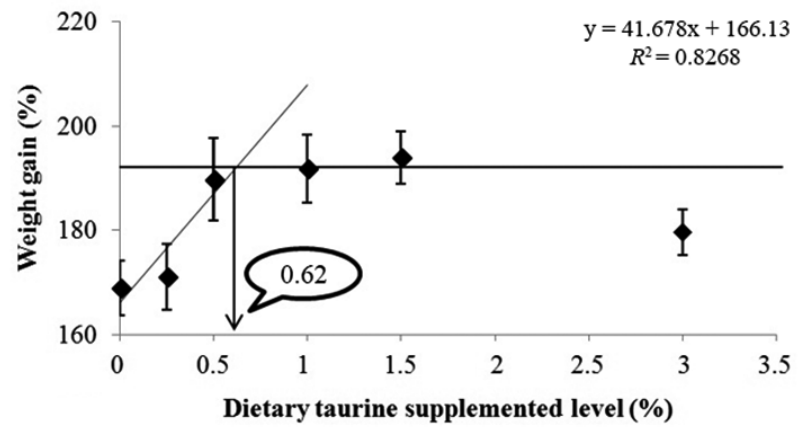

Fig. 1. Broken-line analysis of weight gain (\%) in juvenile rock bream fed the different levels of taurine for 8 weeks. Values on the X-axis are the taurine supplemented levels in experimental diets. Broken line regression analysis based on weight gain indicates an optimum dietary taurine supplementation level of $0.62 \%$. Error bars represent standard deviation $(n=3)$.

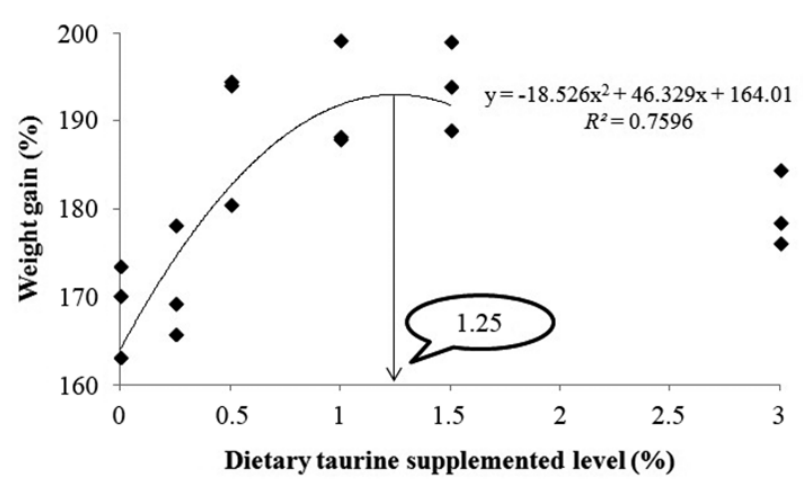

Fig. 2. Second-degree polynomial regression of weight gain (\%) in juvenile rock bream fed the different levels of taurine for 8 weeks. Values on the $\mathrm{X}$-axis are the taurine supplemented levels in experimental diets. The second-degree polynomial regression analysis of weight gain indicates a maximum effective dietary taurine supplementation level of $1.25 \%$.

teau for the $\mathrm{Tau}_{1.0}$ diet. Fish fed the $\mathrm{Tau}_{1.0}, \mathrm{Tau}_{1.5}$ and $\mathrm{Tau}_{3.0}$ diets had a significantly higher whole-body taurine content than fish fed the other experimental diets. Conversely, the whole-body sulfur amino acid content increased with increasing dietary taurine up to $\mathrm{Tau}_{0.5}$, and then declined steadily. Fish

Table 3. Whole-body proximate composition (\% dry matter) of juvenile rock bream fed the experimental diets for 8 weeks'

\begin{tabular}{|c|c|c|c|c|c|c|c|}
\hline & \multicolumn{6}{|c|}{ Diets $^{2}$} & \multirow{2}{*}{ Pooled SEM $^{3}$} \\
\hline & Control & $\operatorname{Tau}_{0.25}$ & $\mathbf{T a u}_{0.5}$ & $\mathbf{T a u}_{1.0}$ & $\operatorname{Tau}_{1.5}$ & $\mathbf{T a u}_{3.0}$ & \\
\hline Crude protein $(\%)$ & $58.02^{\mathrm{b}}$ & $59.50^{\mathrm{ab}}$ & $60.41^{\mathrm{ab}}$ & $62.12^{\mathrm{a}}$ & $60.79^{\mathrm{ab}}$ & $59.85^{\mathrm{ab}}$ & 0.13 \\
\hline Crude lipid (\%) & $21.43^{\mathrm{a}}$ & $21.38^{\mathrm{a}}$ & $19.51^{\mathrm{ab}}$ & $18.32^{\mathrm{ab}}$ & $17.57^{\mathrm{b}}$ & $17.79^{\mathrm{b}}$ & 0.13 \\
\hline Moisture (\%) & 73.60 & 76.02 & 75.30 & 75.09 & 75.77 & 74.14 & 0.09 \\
\hline Ash (\%) & 16.69 & 17.12 & 16.26 & 16.79 & 16.56 & 15.97 & 0.07 \\
\hline
\end{tabular}

${ }^{1}$ Means of three sampling batches from each tank; values in the same row with different letters are significantly different $(P<0.05)$.

${ }^{2}$ Refer to Table 1.

${ }^{3}$ Pooled standard error of mean: SD $/ \sqrt{ } n, n=3$ replicated tanks of fish per diet treatment. 

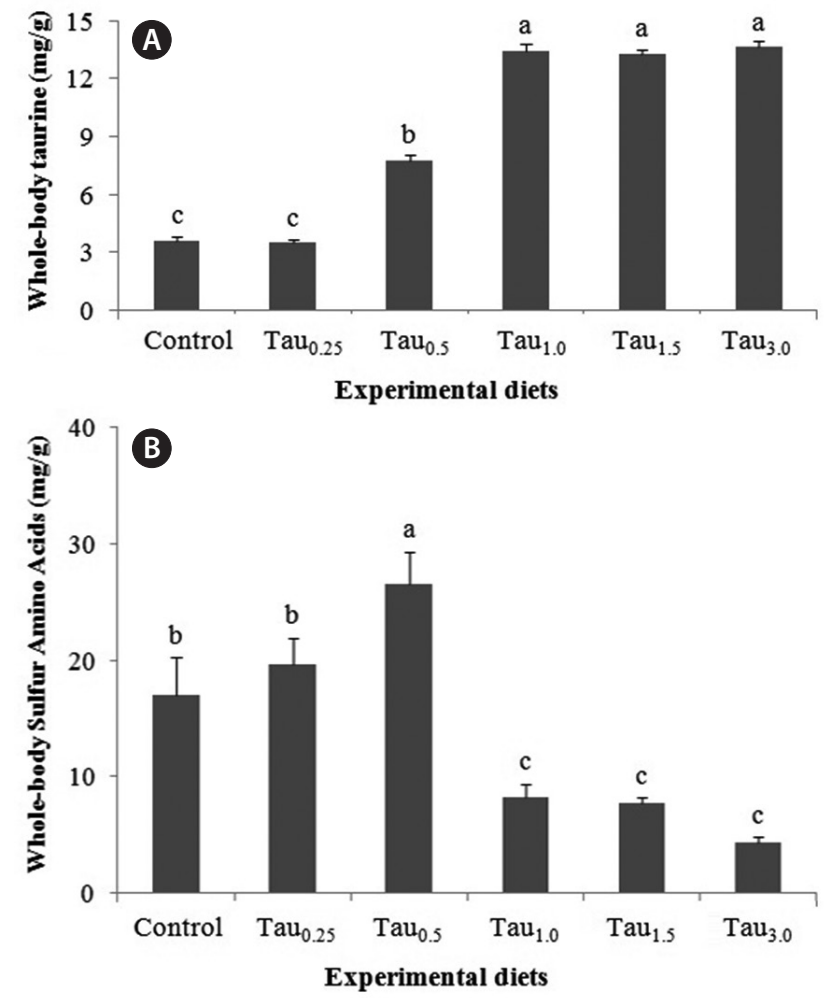

Fig. 3. (A) Taurine and (B) sulfur amino acids (methionine plus cysteine) contents in whole-body of juvenile rock bream fed experimental diets prepared by adding taurine at $0 \%, 0.25 \%, 0.5 \%, 1.0 \%, 1.5 \%$ and $3.0 \%$ (Control, Tau0.25, Tau0.5, Tau1.0, Tau1.5, and Tau3.0, respectively). Different letter on each bar represents significant difference $(P<0.05)$. Error bars represent standard deviation.

fed the Control, $\mathrm{Tau}_{0.25}$ and $\mathrm{Tau}_{0.5}$ diets had significantly higher whole-body sulfur amino acid contents than fish fed the $\mathrm{Tau}_{1.0}$, $\mathrm{Tau}_{1.5}$ and $\mathrm{Tau}_{3.0}$ diets.

\section{Discussion}

Our results suggested a positive effect of dietary taurine on the growth performance of juvenile rock bream. ANOVA of the tested growth parameters indicated no benefits of supplementation with more than $0.5 \%$ taurine; fish fed diets with higher levels of taurine did not display any further improvement in growth performance. However, broken line regression analysis based on WG indicated an optimum dietary taurine supplementation level of $0.62 \%$, which corresponds to a requirement of $7.0 \mathrm{mg}$ taurine/g diet. Moreover, second-degree regression analysis of WG indicated that the maximum dietary taurine supplementation level was $1.25 \%$, which indicates that juvenile rock bream can effectively utilize up to $13.3 \mathrm{mg}$ taurine/g diet. The growth performance results indicated that excessive taurine supplementation $\left(\mathrm{Tau}_{1.0}\right.$ and $\left.\mathrm{Tau}_{1.5}\right)$ did not reduce growth compared with the optimum level of taurine supplementation $\left(\mathrm{Tau}_{0.5}\right)$. However, supplementation with the highest dietary taurine level $\left(\mathrm{Tau}_{3.0}\right)$ resulted in a significant decrease in growth, suggesting that excessive taurine supplementation retards growth by reducing feed intake, as has been reported for olive flounder Paralichthys olivaceus (Park et al., 2002), rainbow trout Oncorhynchus mykiss (Gaylord et al., 2007) and turbot Scophthalmus maximus (Qi et al., 2012).

Dietary taurine supplementation has not only shown positive effects on growth performance but has also been reported to be essential in several species. Park et al. (2002) and Kim et al. $(2005 \mathrm{a}, 2005 \mathrm{~b})$ reported that the dietary taurine level for the optimum growth of olive flounder ranges from 14-16 $\mathrm{mg}$ taurine/g diet. Also, flounder fed diets supplemented with $10 \mathrm{mg}$ taurine/g diet exhibited superior growth, not only relative to a basal diet, but also to those diets supplemented with gamma-aminobutyric acid (GABA) and $\beta$-alanine (Kim et al., 2003). Qi et al. (2012) suggested $10 \mathrm{mg}$ taurine/g diet as the dietary taurine requirement for normal growth and feed efficiency in turbot. Similar to our results, Qi et al. (2012) reported that with increasing dietary taurine intake, the growth performance increased and then plateaued, with no beneficial effects of taurine supplementation greater than the required level. Additionally, the taurine requirement for growth and feed efficiency enhancement of red sea bream, Pagrus major, was estimated to be $5 \mathrm{mg}$ taurine/g diet (Matsunari et al., 2008). Moreover, taurine supplementation was shown to be indispensable in diets containing high levels of plant-based proteins (Takagi et al., 2006; Gaylord et al., 2007; Lunger et al., 2007; Espe et al., 2012). Takagi et al. (2011) reported that taurine dietary supplementation of soy protein concentrate is essential for maintenance of the growth performance and a normal physiological condition in red sea bream.

Taurine supplementation has been reported to be essential for rock bream (Lim et al., 2013). A fish-meal-based diet was used as a control, and diets supplemented with $0.2 \%, 0.4 \%$, $0.8 \%, 1.2 \%$ or $1.6 \%$ taurine were fed to triplicate groups of juvenile rock bream (initial body weight of $13.5 \mathrm{~g}$ ) to apparent satiation for 8 weeks. Similar to our results, the fish readily accepted all of the experimental diets and maintained normal behavior during the feeding trial. The growth and feed utilization were significantly improved by taurine supplementation up to $0.8 \%$, but plateaued thereafter. The optimum dietary taurine level was determined by a broken line regression analysis based on weight gain to be $0.88 \%$ ( $8.8 \mathrm{mg}$ taurine/g diet). However, their results suggested no significant differences in WG, SGR, FE and PER between fish fed $0.8 \%$ and $0.4 \%$ taurine-supplemented diets.

In our study, the taurine content in whole-body increased with increasing dietary taurine until fish fed taurine at $1 \%$ and then reached a plateau. Similarly, Park et al. (2002), Kim et al. (2003, 2005a, 2005b, 2008b), Matsunari et al. (2008) and Qi et al. (2012) reported a positive linear relationship between whole-body taurine accumulation and the dietary taurine level. The major pathway for taurine synthesis from methionine in mammals is believed to involve the 
transformation of methionine to cystathionine by cystathionine synthetase, transformation of cystathionine to cysteine by cystathionase, oxidation of cysteine to cysteinesulfinate, decarboxylation of cysteinesulfinate to hypotaurine, and further oxidation of hypotaurine to taurine (Worden and Stipanuk, 1985). Therefore, the low whole-body taurine levels of fish fed the Control and $\mathrm{Tau}_{0.25}$ diets suggest a deficiency in taurine biosynthesis in juvenile rock bream. The opposite relationship was found for sulfur amino acid whole-body content; methionine and cysteine contents decreased with increasing taurine supplementation. A reduction in wholebody cystathionine content with increasing dietary taurine level has been reported for olive flounder (Park et al., 2002). Similarly, Kim et al. (2003, 2005a) suggested that cystathionine accumulates in the tissues of flounder fed a diet without taurine supplementation and that the accumulated cystathionine may be used for taurine biosynthesis. The results of our previous study of the taurine biosynthesis pathway (Worden and Stipanuk, 1985), and research into rock bream (Lim et al., 2013), suggest a taurine insufficiency in the Control and low taurine $\left(\mathrm{Tau}_{0.25}\right)$ diets. Indeed, the accumulation of sulfur amino acids in the whole-body of rock bream fed a taurine-insufficient diet suggests that juvenile rock bream accumulate sulfur amino acids to facilitate posterior taurine biosynthesis.

In our study, while the whole-body crude protein content of fish fed the experimental diets was affected by taurine only slightly, the crude lipid content displayed a linear decrease with increasing dietary taurine level. Similar results were reported in flounder (Kim et al., 2008b), Atlantic salmon (Espe et al., 2012), turbot (Qi et al., 2012) and red sea bream (Matsunari et al., 2008). According to Espe et al. (2012), the lower crude lipid whole-body content indicates that the addition of a low concentration of taurine to high-plant-protein diets influences lipid metabolism and storage, concomitantly affecting general metabolism. In particular, taurine plays a role in fat digestion by conjugating bile acids, such as cholic acid or chenodeoxycholic acid, in the liver. In lipid metabolism, taurine is involved in the degradation of cholesterol metabolites and participates in micelle formation, thus contributing to fat absorption in the small intestine (Yokogoshi et al., 1999).

In summary, the optimum dietary taurine level to improve the growth of juvenile rock bream, $O$. fasciatus, ranged from 0.50 to $0.62 \mathrm{mg}$ taurine/g diet, based on ANOVA and broken line regression analysis of WG. In addition to higher growth performance, taurine supplementation affected lipid metabolism, as indicated by reduced whole-body lipid levels.

\section{Acknowledgments}

The authors would like to thank Korea Bio-gen (Cheonan, Korea) for their contribution of taurine powder. Thanks are also due to all the member of the Feed and Foods Nutrition
Research Center for their cooperation throughout the feeding trial and analysis. This research was financially supported by Pukyong National University (201382014), and by the exchange student program from the Ministry of Education of Korea (KGSP/NIIED).

\section{References}

AOAC (Association of Official Analytical Chemists). 2006. Official Methods of Analysis. 18th ed. Association of Official Analytical Chemists, Gaithersburg, MD, US.

Baker DH. 1986. Problems of pitfalls in animal experiments designed to establish dietary requirements for essential nutrients. J Nutr 116, 2339-2349.

El-Sayed AM. 2013. Is dietary taurine supplementation beneficial for farmed fish and shrimp? a comprehensive review. Rev Aquac 5, $1-15$.

Espe M, Ruohonen K and El-Mowafi A. 2012. Effect of taurine supplementation on the metabolism and body lipid-to-protein ratio in juvenile Atlantic salmon (Salmo salar). Aquac Res 43, 349-360.

Gaylord TG, Barrows FT, Teague AM, Johansen KA, Overturf KE and Shepherd B. 2007. Supplementation of taurine and methionine to all-plant protein diets for rainbow trout (Oncorhynchus mykiss). Aquaculture 269, 514-524.

Hwang UG, Lee JS and Kang JC. 2013. Responses of the hepatic microsomal cytochrome $\mathrm{P} 450$ monooxygenase system in rock bream Oplegnathus fasciatus exposed to tributyltin (TBT). Fish Aquat Sci $16,261-265$.

Kang YJ, Lee SM, Hwang HK and Bai SC. 1998. Optimum dietary protein and lipid levels on growth in parrot fish (Oplegnathus fasciatus). Kor J Aquat Sci 11, 1-10.

Kim SK, Takeuchi T, Yokoyama M and Murata Y. 2003. Effect of dietary supplementation with taurine, beta-alanine and GABA on the growth of juvenile and fingerling Japanese flounder Paralichthys olivaceus. Fish Sci 69, 242-248.

Kim SK, Takeuchi T, Akimoto A, Furuita H, Yamamoto T, Yokoyama M and Murata Y. 2005a. Effect of taurine supplemented practical diet on growth performance and taurine contents in whole body and tissues of juvenile Japanese flounder Paralichthys olivaceus. Fish Sci 71, 627-632.

Kim SK, Takeuchi T, Yokoyama M, Murata Y, Kaneniwa M and Sakakura Y. 2005b. Effect of dietary taurine levels on growth and feeding behavior of juvenile Japanese flounder Paralichthys olivaceus. Aquaculture 250, 765-774.

Kim KM, Lee JU, Kim JW, Han SJ, Kim KD and Jo JY. 2008a. Daily feeding rates of parrot fish Oplegnathus fasciatus fed extruded pellet at the different water temperatures. Kor J Aquat Sci 21, 294-298.

Kim SK, Matsunari H, Nomura K, Tanaka H, Yokoyama M, Murata Y, Ishihara $\mathrm{K}$ and Takeuchi T. 2008b. Effect of dietary taurine and lipid contents on conjugated bile acid composition and growth performance of juvenile Japanese flounder Paralichthys olivaceus. Fish Sci 74, 875-881. 
Kim JH, Jeong DS and Kang JC. 2013a. Toxic effects on the nonspecific immune system of the rock bream Oplegnathus fasciatus upon exposure to di-2-ethylhexyl phthalate. Fish Aquat Sci 16, 171-176.

Kim SS, Rahimnejad S, Kim KW and Lee KJ. 2013b. Partial replacement of fish meal with Spirulina pacifica in diets for parrot fish (Oplegnathus fasciatus). Turk J Fish Aquat Sci 13, 197-204.

Ko GY, Lim SJ, Kim SS, Oh DH and Lee KJ. 2008. Effects of dietary supplementation of scoria on growth and protein digestibility in juvenile parrot fish Oplegnathus fasciatus and olive flounder Paralichthys olivaceus. Kor J Aquat Sci 21, 133-138.

Kuzmina VV, Gavrovskaya LK and Ryzhova OV. 2010. Taurine. Effect on exotrophia and metabolism in mammals and fish. J Evol Biochem Physiol 46, 19-27.

Lim SJ and Lee KJ. 2009. Partial replacement of fish meal by cottonseed meal and soybean meal with iron and phytase supplementation for parrot fish Oplegnathus fasciatus. Aquaculture 290, 283-289.

Lim SJ, Oh DH, Khosravi S, Cha JH, Park SH, Kim KW and Lee KJ. 2013. Taurine is an essential nutrient for juvenile parrot fish Oplegnathus fasciatus. Aquaculture 414/415, 274-279.

Lunger AN, McLean E, Gaylord TG, Kuhn D and Craig SR. 2007. Taurine supplementation to alternative dietary proteins used in fish meal replacement enhances growth of juvenile cobia (Rachycentron canadum). Aquaculture 271, 401-410.

Matsunari H, Yamamoto T, Kim SK, Goto T and Takeuchi T. 2008. Optimum dietary taurine level in casein-based diet for juvenile red sea bream Pagrus major. Fish Sci 74, 347-353.

MOMAF. 2014. Statistical database for fisheries production [Internet]. Korea National Statistical Office, Daejeon, Korea. Accessed 10 Mar 2014, http://www.fips.go.kr.

NRC (National Research Council). 2011. Nutritient Requirements of Fish and Shrimp. National Academies Press, Washington, DC, US.

Park GS, Takeuchi T, Yokoyama M and Seikai T. 2002. Optimal dietary taurine level for growth of juvenile Japanese flounder Paralichthys olivaceus. Fish Sci 68, 824-829.

Qi G, Ai Q, Mai K, Xu W, Liufu Z, Yun B and Zhou H. 2012. Effects of dietary taurine supplementation to a casein-based diet on growth performance and taurine distribution in two sizes of juvenile turbot (Scophthalmus maximus L.). Aquaculture 358/359, 122-128.

Rhodes M and Davis DA. 2011. Taurine: critical supplement for marine fish feed. Glob aquac advocate Nov/Dec, 34-35.

Robbins KR, Norton HW and Baker DH. 1979. Estimation of nutrient requirements from growth data. J Nutr 109, 1710-1714.

Takagi S, Murata H, Goto T, Hayashi M, Hatate H, Endo M, Yamashita $\mathrm{H}$ and Ukawa M. 2006. Hemolytic suppression roles of taurine in yellowtail Seriola quinqueradiata fed non-fishmeal diet based on soybean protein. Fish Sci 72, 546-555.

Takagi S, Murata H, Goto T, Hatate H, Endo M, Yamashita H, Miyatake $\mathrm{H}$ and Ukawa M. 2011. Role of taurine deficiency in inducing green liver symptom and effect of dietary taurine supplementation in improving growth in juvenile red sea bream Pagrus major fed non-fishmeal diets based on soy protein concentrate. Fish Sci 77, 235-244.

Wang X, Kim KW, Bai SC, Huh MD and Cho BY. 2003. Effects of the different levels of dietary vitamin $\mathrm{C}$ on growth and tissue ascorbic acid changes in parrot fish (Oplegnathus fasciatus). Aquaculture 215, 203-211.

Worden JA and Stipanuk MK. 1985. A comparison by species, age and sex of cysteinesulfinate decarboxylase activity and taurine concentration in liver and brain of animals. Comp Biochem Physiol 82, 233-239.

Yokogoshi H, Mochizuki H, Nanami K, Hida Y, Miyachi F and Oda H. 1999. Dietary taurine enhances cholesterol degradation and reduces serum and liver cholesterol concentrations in rats fed a highcholesterol diet. J Nutr 129, 1705-1712. 